\title{
Association of laboratory parameters and genetic polymorphisms with ischemic stroke in Chinese Han population
}

\author{
JIAYONG WANG ${ }^{1,2^{*}}$, ZUJUN SUN $^{2 *}$, YIBAO YANG $^{2}$, JUNLU WU $^{2}$, \\ WENQIANG QUAN $^{2}$, XINGCAI CHEN $^{3}$, PEIHUA NI $^{1}$ and DONG LI ${ }^{2}$
}

${ }^{1}$ Faculty of Medical Laboratory Science, Ruijin Hospital, School of Medicine, Shanghai Jiaotong University, Shanghai 200020; ${ }^{2}$ Department of Clinical Laboratory, Shanghai Tongji Hospital, Tongji University School of Medicine, Shanghai 200065; ${ }^{3}$ Department of Human Anatomy, Guangxi Medical University, Nanning, Guangxi 530021, P.R. China

Received July 16, 2020; Accepted February 9, 2021

DOI: $10.3892 / \mathrm{etm} .2021 .9921$

\begin{abstract}
Numerous genetic polymorphisms and clinical laboratory parameters are associated with ischemic stroke (IS). However, the results of such studies have frequently been inconsistent. The aim of the present study was to evaluate associations between clinical laboratory parameters with genetic polymorphisms that influence the risk of IS in a Chinese Han population. Clinical laboratory parameters were measured by an automatic biochemical analyzer. Genotype and allele frequencies of the polymorphisms angiotensin-converting enzyme (ACE) D/I, methylene tetrahydrofolate reductase (MTHFR) C677T and $\beta$-fibrinogen $(\beta-\mathrm{Fg}) \mathrm{A} / \mathrm{G}, 455 / 148 \mathrm{~T} / \mathrm{C}$ were characterized by restriction fragment length polymorphism-PCR. Furthermore, the gene polymorphisms plasminogen activator inhibitor (PAI)-14G/5G and apolipoprotein E (ApoE) $\varepsilon 2,3,4$ were characterized by allele-specific PCR. The associations of genotype and allele frequencies of the six risk genes in different groups with clinical laboratory parameters were analyzed by chi-square tests. The distribution maps of the polymorphisms of the six genes and clinical laboratory parameters were compared between a control group of 336 healthy individuals and 762 patients with IS. Certain laboratory parameters were associated with ACE I/D, $\beta-\mathrm{Fg}-455 \mathrm{~A} / \mathrm{G}$ and PAI-1 4G/5G. The D allele of ACE I/D was associated with high levels of total cholesterol and
\end{abstract}

Correspondence to: Dr Peihua Ni, Faculty of Medical Laboratory Science, Ruijin Hospital, School of Medicine, Shanghai Jiaotong University, 126 Ruijin Road, Shanghai 200020, P.R. China

E-mail: nipeihua@shsmu.edu.cn

Dr Dong Li, Department of Clinical Laboratory, Shanghai Tongji Hospital, Tongji University School of Medicine, 389 Xincun Road, Shanghai 200065, P.R. China

E-mail: lidong@tongji.edu.cn

${ }^{*}$ Contributed equally

Key words: ischemic stroke, genetic polymorphism, laboratory parameter, hyperlipidemia, diabetes low-density lipoprotein cholesterol (LDL-C). Furthermore, high levels of fasting blood glucose, triglyceride and LDL-C were risk factors for IS. There were significant differences in the genotype frequencies of ACE I/D, $\beta-\mathrm{Fg}-455 \mathrm{~A} / \mathrm{G}$ and $\beta-\mathrm{Fg}-148 \mathrm{~T} / \mathrm{C}$ between the IS and the control group. In conclusion, clinical laboratory parameters were associated with the risk of polymorphisms of IS-related genes. The present results support the determination of a range of control values of clinical laboratory parameters for common genotypes in patients with diabetes and hyperlipidemia as a strategy for the early prevention of IS.

\section{Introduction}

Stroke is an episode of neurological dysfunction caused by focal cerebral, spinal or retinal infarction, and has become the second leading cause of disability and death in adults worldwide $(1,2)$. Ischemic stroke (IS) is the most common type of stroke. There are multiple risk factors for IS, which include age, sex, body mass index (BMI), hyperlipidemia, hypertension, diabetes, smoking and particulate matter 2.5 pollution $(3,4)$.

Previous studies have examined the roles of polymorphisms in numerous genes involved in the pathogenesis of IS, including C-C motif chemokine 11, paraoxonase 1, angiotensin-converting enzyme (ACE), and methylenetetrahydrofolate reductase (MTHFR) (5-7). It has been reported that the ACE I/D polymorphism is significantly associated with IS in different ethnic groups (8). However, other studies failed to observe this association $(9,10)$. Patients with the MTHFR 677TT genotype have vascular occlusion, infarct and increased levels of blood homocysteine, which form the basis for the association of this genetic polymorphism with hypertension (11). Polymorphism of MTHFR has important roles in hypertension and IS, both of which are caused by atherosclerotic vascular disease (12). Numerous studies have been performed to investigate the potential association between polymorphisms of $\beta$ fibrinogen $(\beta-\mathrm{Fg})$ and the risk of IS. However, the results of these studies were inconsistent, and the sample sizes of individual studies were inadequate to draw definite conclusions (13-15). The 4G/5G polymorphism in the promoter of the plasminogen activator inhibitor-1 gene (PAI-1) is one of the most frequently studied (16). A single 
$4 \mathrm{G}$ allele is considered to be a risk factor for coronary artery disease and the $4 \mathrm{G} / 4 \mathrm{G}$ genotype is thought to increase the risk of coronary artery disease $(17,18)$. Several studies addressed the association between the $4 \mathrm{G} / 5 \mathrm{G}$ polymorphism and stroke, but these results were inconsistent $(19,20)$. Although PAI-1 may be an important factor in the occurrence of IS, the association between PAI-1 gene polymorphisms and the risk of IS has remained to be elucidated. Apolipoprotein E (ApoE) polymorphism involves a single amino substitution and results in three major alleles ( $\varepsilon 2, \varepsilon 3$ and $\varepsilon 4)$ with six corresponding phenotypes ( $\varepsilon 2 / \varepsilon 2, \varepsilon 3 / \varepsilon 3, \varepsilon 4 / \varepsilon 4, \varepsilon 2 / \varepsilon 3, \varepsilon 2 / \varepsilon 4$ and $\varepsilon 3 / \varepsilon 4)(21)$. The relationship between ApoE genotype and stroke is unclear because of inconsistent study results. Certain reports indicated a positive association between ApoE4-containing genotypes and stroke, but others indicated no relationships between ApoE isoforms and dyslipidemia or stroke $(22,23)$. The influence of the gene polymorphisms on clinical laboratory parameters of IS has not been described in the Chinese Han population, to the best of our knowledge.

The aim of the present study was to evaluate potential associations between polymorphisms in six genes, namely ACE D/I, MTHFR C677T, $\beta$-Fg A/G, 455/148T/C, PAI-1, $4 \mathrm{G} / 5 \mathrm{G}$ and ApoE $\varepsilon 2,3,4$, and clinical laboratory parameters of IS in the Chinese Han population. Such data may be used to provide a control range of laboratory parameters according to genotype for the early prevention of IS in patients with diabetes and hyperlipidemia.

\section{Patients and methods}

Patients. The medical records of all newly diagnosed patients with proven diabetes and hyperlipidemia who were admitted to Shanghai Tongji Hospital (Shanghai, China) from October 2016 to November 2018 were examined. The present study was approved by the ethics committee of Shanghai Tongji Hospital (Shanghai, China) and was conducted according to the Declaration of Helsinki. All participants provided informed consent in written form. For participants who were unable to communicate, written consent was obtained from their legal relatives.

Patients who met the following criteria were included: i) Fasting blood glucose $(\mathrm{FBG}) \geq 7.0 \mathrm{mmol} / \mathrm{l}$ or 2 -h oral glucose tolerance test $\geq 11.1 \mathrm{mmol} / \mathrm{l}$; ii) triglyceride (TG) $\geq 1.7 \mathrm{mmol} / 1$ orlow-density lipoprotein cholesterol (LDL-C) $\geq 3.37 \mathrm{mmol} / 1$ or total cholesterol $(\mathrm{CHOL}) \geq 5.18 \mathrm{mmol} / \mathrm{l}$; iii) a diagnosis of IS meeting the standards of Chinese guidelines for the diagnosis and treatment of acute ischemic stroke in 2014 (24), which were issued by Chinese Medical Association; and iv) Chinese Han population and unrelated to other participants in the study.

Patients with a diagnosis of any of the following conditions were excluded: i) Other types of cerebrovascular disease, including intracranial hemorrhage, subarachnoid hemorrhage, cerebrovascular malformation or cerebral aneurysm; and ii) severe systemic diseases, including cancer, severe inflammatory disease or serious chronic diseases (e.g. hepatic failure or renal failure).

The control group comprised 336 individuals without a history of cerebrovascular disease who were physical examined in the hospital during the same period. Age, sex, use of oral contraceptives and history of thrombotic events or drug abuse were recorded. The baseline characteristics of patients and controls are presented in Table SI.

Serum lipid, glucose and transaminase measurement. Blood samples ( $\sim 3 \mathrm{ml}$ fasting blood) were collected from each study participant and then separated by centrifugation at $840 \mathrm{x} \mathrm{g}$ for $10 \mathrm{~min}$ in a SPINCHRON ${ }^{\mathrm{TM}}$ DLX centrifuge (Beckman Coulter). Serum levels of FBG, CHOL, TG, LDL-C, high-density lipoprotein cholesterol (HDL-C), alanine aminotransferase (ALT) and aspartate aminotransferase (AST) were analyzed by an automatic biochemical analyzer (DXC800; Beckman Coulter).

DNA extraction and genetic analysis. Genomic DNA was extracted from peripheral blood leukocytes using a TIANamp Genomic DNA kit (Tiangen Biotech) following the protocol of the manufacturer. Polymorphisms were genotyped using allele-specific PCR and restriction fragment length polymorphism analysis described in Data S1. PCR primers were synthesized by Sangon Biotech Co., Ltd.; the sequences are listed in Table SII. Amplified PCR products of intron 16 of ACE were separated on a $2 \%$ agarose gel (Bio-Rad Laboratories, Inc.) (Fig. 1). The presence of 191-bp fragments indicated the D allele, 480-bp fragments represented the I allele and 191- and 480-bp fragments represented the $\mathrm{D} / \mathrm{I}$ allele. Amplification products of $\beta-\mathrm{Fg}-455$ were digested by HaeIII (FD0154; Thermo Fisher Scientific, Inc.) and then separated on a $2 \%$ agarose gel (Fig. 1). The presence of 343-, 383- and 575-bp fragments represented the GG allele; $343-$ and 958-bp fragments represented the AA allele, and 343-, 383-, 575- and 958-bp fragments represented the G/A allele. Amplification products of $\beta$-Fg-148 were digested by HindIII (FD0505; Thermo Fisher Scientific, Inc.) (Fig. 1). The presence of 100- and 200-bp fragments represented the CC allele, the presence of 300-bp fragments represented the TT allele and the presence of 100-, 200- and 300-bp fragments represented the T/C allele. Amplification products of MTHFR were digested by HinfI (FD0804; Thermo Fisher Scientific, Inc.) (Fig. 1). The presence of 100- and 200-bp fragments represented the TT allele, 300-bp fragments represented the CC allele and 100-, 200- and 300-bp fragments represented the T/C allele. Amplification products of PAI-1and ApoE ع2,3,4 gene alleles were separated on a $2 \%$ agarose gel and subjected to first-generation sequencing by Genewiz, Inc..

Statistical analysis. SPSS statistical software version 21.0 (IBM Corp.) was used for statistical analysis. Pearson's chi-squared test or Fisher's exact test were used for statistical comparisons of count data. Continuous variables are expressed as the mean \pm standard deviation. Receiver operating characteristic (ROC) curve analysis was used to analyze laboratory parameters related to IS. Logistic regression was used to analyze the models 1 and 2 . $\mathrm{P}<0.05$ was considered to indicate statistical significance.

\section{Results}

Relationships between laboratory parameters and genotype and allele frequencies. Table I indicates the associations between laboratory parameters and the ACE I/D, $\beta$-Fg-455 A/G and PAI-1 4G/5G gene polymorphisms. The D allele of 
Table I.Association of laboratory parameters with genotype frequencies of ACE I/D, MTHFR C677T, $\beta$-Fg-455A/G, $\beta$-Fg-148T/C, PAI-1 4G/5G and ApoE ع2-4.

\begin{tabular}{|c|c|c|c|c|c|c|c|c|}
\hline \multirow[b]{2}{*}{ Item } & \multicolumn{2}{|c|}{$\mathrm{FBG}(\mathrm{mmol} / \mathrm{l})$} & \multicolumn{2}{|c|}{$\mathrm{TC}(\mathrm{mmol} / \mathrm{l})$} & \multicolumn{2}{|c|}{ TG (mmol/l) } & \multicolumn{2}{|c|}{ LDL-C (mmol/l) } \\
\hline & $\geq 7.00$ & $<7.00$ & $\geq 5.18$ & $<5.18$ & $\geq 1.70$ & $<1.70$ & $>3.37$ & $\leq 3.37$ \\
\hline \multicolumn{9}{|l|}{ ACE I/D } \\
\hline II & $23(51.1)$ & $142(48.5)$ & $14(32.6)$ & $151(51.2)$ & $21(42.0)$ & $144(50.0)$ & $15(31.3)$ & $150(51.7)$ \\
\hline $\mathrm{I} / \mathrm{D}$ & $17(37.8)$ & $108(36.8)$ & $20(46.5)$ & 105 (35.6) & $19(38.0)$ & $106(36.8)$ & $24(50.0)$ & $101(34.8)$ \\
\hline DD & $5(11.1)$ & $43(14.7)$ & $9(20.9)$ & $39(13.2)$ & $10(20.0)$ & $38(13.2)$ & $9(18.8)$ & $39(13.4)$ \\
\hline$\chi^{2} / \mathrm{P}$-value & \multicolumn{2}{|c|}{$0.414 / 0.813$} & \multicolumn{2}{|c|}{$5.448 / 0.066$} & \multicolumn{2}{|c|}{$1.964 / 0.374$} & \multicolumn{2}{|c|}{$6.915 / 0.032$} \\
\hline \multicolumn{9}{|c|}{ MTHFR C677T } \\
\hline $\mathrm{CC}$ & $15(33.3)$ & $96(32.8)$ & $12(27.9)$ & $99(33.5)$ & $19(38.0)$ & $92(31.9)$ & $15(31.3)$ & $96(33.1)$ \\
\hline $\mathrm{T} / \mathrm{C}$ & $25(55.6)$ & $144(49.1)$ & $21(48.8)$ & $148(50.2)$ & $21(42.0)$ & $148(51.4)$ & $23(47.9)$ & $146(50.3)$ \\
\hline $\mathrm{TT}$ & $5(11.1)$ & $53(18.1)$ & $10(23.3)$ & $48(16.3)$ & $10(20.0)$ & 48 (16.7) & $10(20.8)$ & $48(16.6)$ \\
\hline$\chi^{2} / \mathrm{P}$-value & \multicolumn{2}{|c|}{$1.431 / 0.489$} & \multicolumn{2}{|c|}{$1.445 / 0.485$} & \multicolumn{2}{|c|}{$1.503 / 0.472$} & \multicolumn{2}{|c|}{$0.532 / 0.767$} \\
\hline \multicolumn{9}{|c|}{$\beta-F g-455 \mathrm{~A} / \mathrm{G}$} \\
\hline $\mathrm{GG}$ & $22(48.9)$ & $187(63.8)$ & $22(51.2)$ & $187(63.4)$ & $30(60.0)$ & $179(62.2)$ & $25(52.1)$ & $184(63.4)$ \\
\hline $\mathrm{G} / \mathrm{A}$ & $21(46.7)$ & $95(32.4)$ & $21(48.8)$ & $95(32.2)$ & $17(34.0)$ & 99 (34.4) & $23(47.9)$ & $93(32.1)$ \\
\hline AA & $2(4.4)$ & $11(3.8)$ & $0(0.0)$ & $13(4.4)$ & $3(6.0)$ & $10(3.5)$ & $0(0.0)$ & $13(4.5)$ \\
\hline$\chi^{2} / \mathrm{P}$-value & \multicolumn{2}{|c|}{$3.761 / 0.152$} & \multicolumn{2}{|c|}{$5.828 / 0.054$} & \multicolumn{2}{|c|}{$0.741 / 0.690$} & \multicolumn{2}{|c|}{$6.026 / 0.049$} \\
\hline \multicolumn{9}{|l|}{$\beta-\mathrm{Fg}-148 \mathrm{~T} / \mathrm{C}$} \\
\hline $\mathrm{CC}$ & $26(57.8)$ & $166(56.7)$ & $23(53.5)$ & $169(57.3)$ & $29(58.0)$ & $163(56.6)$ & $26(54.2)$ & $166(57.2)$ \\
\hline $\mathrm{T} / \mathrm{C}$ & $17(37.8)$ & $106(36.2)$ & $19(44.2)$ & $104(35.3)$ & $18(36.0)$ & $105(36.5)$ & $21(43.8)$ & $102(35.2)$ \\
\hline $\mathrm{TT}$ & $2(4.4)$ & $21(7.2)$ & $1(2.3)$ & $22(7.5)$ & $3(6.0)$ & $20(6.9)$ & $1(2.1)$ & $22(7.6)$ \\
\hline$\chi^{2} / \mathrm{P}$-value & \multicolumn{2}{|c|}{$0.461 / 0.794$} & \multicolumn{2}{|c|}{$2.371 / 0.306$} & \multicolumn{2}{|c|}{$0.073 / 0.964$} & \multicolumn{2}{|c|}{$2.734 / 0.255$} \\
\hline \multicolumn{9}{|l|}{ PAI-1 4G/5G } \\
\hline 4G4G & $14(31.1)$ & $92(31.4)$ & $14(32.6)$ & $92(31.2)$ & $17(34.0)$ & $89(30.9)$ & $15(31.3)$ & $91(31.4)$ \\
\hline $4 \mathrm{G} / 5 \mathrm{G}$ & $23(51.1)$ & $144(49.1)$ & $22(51.2)$ & $145(49.2)$ & $17(34.0)$ & $150(52.1)$ & $26(54.2)$ & $141(48.6)$ \\
\hline $5 \mathrm{G} 5 \mathrm{G}$ & $8(17.8)$ & 57 (19.5) & $7(16.2)$ & 58 (19.7) & $16(32.0)$ & 49 (17.0) & 7 (14.5) & $58(20.0)$ \\
\hline$\chi^{2} / \mathrm{P}$-value & \multicolumn{2}{|c|}{$0.088 / 0.957$} & 0.27 & 0.871 & 7.92 & 0.019 & 0.88 & 0.642 \\
\hline ApoE ع2-4 & & & & & & & & \\
\hline $\mathrm{E} 2 / 2$ & $0(0.0)$ & $5(1.7)$ & $1(2.3)$ & $4(1.4)$ & $1(2.0)$ & $4(1.4)$ & $1(2.1)$ & $4(1.4)$ \\
\hline $\mathrm{E} 2 / 3$ & 7 (15.6) & $44(15.0)$ & 5 (11.6) & $46(15.6)$ & $10(20.0)$ & $41(14.2)$ & $5(10.4)$ & 46 (15.9) \\
\hline $\mathrm{E} 2 / 4$ & $0(0.0)$ & $5(1.7)$ & $1(2.3)$ & $4(1.4)$ & $1(2.0)$ & $4(1.4)$ & $1(2.1)$ & $4(1.4)$ \\
\hline $\mathrm{E} 3 / 3$ & $33(73.3)$ & 195 (66.6) & $29(67.5)$ & 199 (67.5) & $31(62.0)$ & 197 (68.4) & $32(66.7)$ & $196(67.6)$ \\
\hline $\mathrm{E} 3 / 4$ & $5(11.1)$ & 43 (14.7) & 7 (16.3) & 41 (13.9) & $6(12.0)$ & 42 (14.6) & $9(18.7)$ & $39(13.4)$ \\
\hline $\mathrm{E} 4 / 4$ & $0(0.0)$ & $1(0.3)$ & $0(0.0)$ & $1(0.3)$ & $1(2.0)$ & $0(0.0)$ & $0(0.0)$ & $1(0.3)$ \\
\hline$\chi^{2} / \mathrm{P}$-value & 1.471 & .965 & 2.63 & 0.708 & 6.47 & 0.229 & 3.30 & 0.622 \\
\hline
\end{tabular}

Values are expressed as n (\%). FBG, fasting blood glucose; TC, total cholesterol; TG, triglyceride; LDL-C, low-density lipoprotein cholesterol; $\mathrm{ACE}$, angiotensin-converting enzyme; MTHFR, methylene tetrahydrofolate reductase; $\beta$-Fg, $\beta$-fibrinogen; PAI, plasminogen activator inhibitor; ApoE, apolipoprotein E.
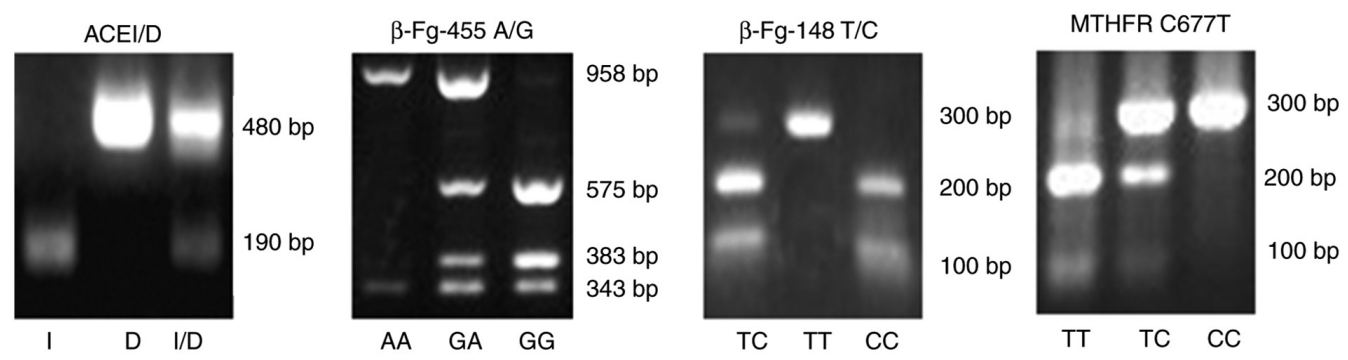

Figure 1. Genotypic determination of the polymorphisms of ACE I/D, $\beta$-Fg-455 A/G, $\beta$-Fg-148 T/C and MTHFR C677T. Agarose gel electrophoresis of PCR products. ACE, angiotensin-converting enzyme; MTHFR, methylene tetrahydrofolate reductase; $\beta$-Fg, $\beta$-fibrinogen. 
Table II. Association of laboratory parameters with allele frequencies of ACE I/D, MTHFR C677T, $\beta$-Fg-455A/G, $\beta$-Fg-148T/C, PAI-1 4G/5G and ApoE ع2-4.

\begin{tabular}{|c|c|c|c|c|c|c|c|c|}
\hline \multirow[b]{2}{*}{ Item } & \multicolumn{2}{|c|}{ FBG $(\mathrm{mmol} / \mathrm{l})$} & \multicolumn{2}{|c|}{ TC $(\mathrm{mmol} / \mathrm{l})$} & \multicolumn{2}{|c|}{ TG $(\mathrm{mmol} / \mathrm{l})$} & \multicolumn{2}{|c|}{ LDL-C (mmol/l) } \\
\hline & $\geq 7.00$ & $<7.00$ & $\geq 5.18$ & $<5.18$ & $\geq 1.70$ & $<1.70$ & $>3.37$ & $\leq 3.37$ \\
\hline \multicolumn{9}{|l|}{ ACE I/D } \\
\hline I & $63(70.0)$ & $392(66.9)$ & $48(55.8)$ & $407(69.0)$ & $61(61.0)$ & $394(68.4)$ & $54(56.3)$ & $401(69.1)$ \\
\hline $\mathrm{D}$ & $27(30.0)$ & $194(33.1)$ & $38(44.2)$ & $183(31.0)$ & $39(39.0)$ & $182(31.6)$ & $42(43.7)$ & $179(30.9)$ \\
\hline$\chi^{2} / \mathrm{P}$-value & \multicolumn{2}{|c|}{$0.324 / 0.559$} & \multicolumn{2}{|c|}{$5.916 / 0.015$} & \multicolumn{2}{|c|}{$2.122 / 0.145$} & \multicolumn{2}{|c|}{$6.217 / 0.013$} \\
\hline \multicolumn{9}{|c|}{ MTHFR C677T } \\
\hline $\mathrm{C}$ & $55(61.1)$ & $336(57.3)$ & $45(52.3)$ & $346(58.6)$ & $59(59.0)$ & $332(57.6)$ & $53(55.2)$ & $338(58.3)$ \\
\hline $\mathrm{T}$ & $35(38.9)$ & $250(42.7)$ & $41(47.7)$ & $244(41.4)$ & $41(41.0)$ & $244(42.4)$ & $43(44.8)$ & $242(41.7)$ \\
\hline$\chi^{2} / \mathrm{P}$-value & \multicolumn{2}{|c|}{$0.456 / 0.500$} & \multicolumn{2}{|c|}{$1.229 / 0.268$} & \multicolumn{2}{|c|}{$0.065 / 0.799$} & \multicolumn{2}{|c|}{$0.318 / 0.573$} \\
\hline \multicolumn{9}{|l|}{$\beta-\mathrm{Fg}-455 \mathrm{~A} / \mathrm{G}$} \\
\hline $\mathrm{G}$ & $65(72.2)$ & $469(80.0)$ & $65(75.6)$ & $469(79.5)$ & $77(77.0)$ & $457(79.3)$ & $73(76.0)$ & $461(79.5)$ \\
\hline A & $25(27.8)$ & $117(20.0)$ & $21(24.4)$ & $121(20.5)$ & $23(23.0)$ & $119(20.7)$ & $23(24.0)$ & $119(20.5)$ \\
\hline$\chi^{2} / \mathrm{P}$-value & \multicolumn{2}{|c|}{$2.869 / 0.090$} & \multicolumn{2}{|c|}{$0.692 / 0.406$} & \multicolumn{2}{|c|}{$0.281 / 0.596$} & \multicolumn{2}{|c|}{$0.588 / 0.443$} \\
\hline \multicolumn{9}{|l|}{$\beta-\mathrm{Fg}-148 \mathrm{~T} / \mathrm{C}$} \\
\hline $\mathrm{C}$ & $69(76.7)$ & 438 (74.7) & $65(75.6)$ & 442 (74.9) & $76(76.0)$ & $431(74.8)$ & $73(76.0)$ & $434(74.8)$ \\
\hline $\mathrm{T}$ & $21(23.3)$ & $148(25.3)$ & $21(24.4)$ & $148(25.1)$ & $24(24.0)$ & $145(25.2)$ & $23(24.0)$ & $146(25.2)$ \\
\hline$\chi^{2} / \mathrm{P}$-value & \multicolumn{2}{|c|}{$0.154 / 0.695$} & \multicolumn{2}{|c|}{$0.018 / 0.894$} & \multicolumn{2}{|c|}{$0.063 / 0.802$} & \multicolumn{2}{|c|}{$0.065 / 0.799$} \\
\hline \multicolumn{9}{|l|}{ PAI-1 4G/5G } \\
\hline $4 \mathrm{G}$ & $51(56.7)$ & $328(56.0)$ & $50(58.1)$ & $329(55.8)$ & $51(51.0)$ & $328(56.9)$ & $56(58.3)$ & $323(55.7)$ \\
\hline $5 \mathrm{G}$ & $39(43.3)$ & $258(44.0)$ & $36(41.9)$ & $261(44.2)$ & $49(49.0)$ & $248(43.1)$ & 40 (41.7) & $257(44.3)$ \\
\hline$\chi^{2} / \mathrm{P}$-value & \multicolumn{2}{|c|}{$0.015 / 0.902$} & \multicolumn{2}{|c|}{$0.172 / 0.678$} & \multicolumn{2}{|c|}{$1.222 / 0.269$} & \multicolumn{2}{|c|}{$0.234 / 0.629$} \\
\hline \multicolumn{9}{|l|}{ ApoE $\varepsilon 2-4$} \\
\hline E2 & $7(7.8)$ & $59(10.1)$ & $8(9.3)$ & $58(9.8)$ & $13(13.0)$ & $53(9.2)$ & $8(8.3)$ & $58(10.0)$ \\
\hline E3 & 78 (86.7) & 477 (81.4) & $70(81.4)$ & 485 (82.2) & $78(78.0)$ & $477(82.8)$ & $78(81.3)$ & $477(82.2)$ \\
\hline $\mathrm{E} 4$ & $5(5.5)$ & $50(8.5)$ & $8(9.3)$ & $47(8.0)$ & $9(9.0)$ & $46(8.0)$ & $10(10.4)$ & $45(7.8)$ \\
\hline$\chi^{2} / \mathrm{P}$-value & 1.53 & 0.465 & 0.19 & /0.908 & 1.60 & 0.448 & 0.95 & 0.619 \\
\hline
\end{tabular}

Values are expressed as n (\%). FBG, fasting blood glucose; TC, total cholesterol; TG, triglyceride; LDL-C, low-density lipoprotein cholesterol; ACE, angiotensin-converting enzyme; MTHFR, methylene tetrahydrofolate reductase; $\beta$-Fg, $\beta$-fibrinogen; PAI, plasminogen activator inhibitor; ApoE, apolipoprotein E.

ACE I/D was associated with high levels of TC and LDL-C, as presented in Table II. Furthermore, a significant association between the $\beta-F g-455 \mathrm{~A} / \mathrm{G}$ polymorphism and LDL-C levels and an association between PAI-1 4G/5G and TG were observed (Table I). The frequency of the $4 \mathrm{G} / 5 \mathrm{G}$ genotype of PAI-1 4G/5G was highest in the $\mathrm{TG}<1.70 \mathrm{mmol} / 1$ group and the frequency of the $4 \mathrm{G} / 5 \mathrm{G}$ genotype was equal to that of the $4 \mathrm{G} 4 \mathrm{G}$ genotype in the $\mathrm{TG} \geq 1.70 \mathrm{mmol} / \mathrm{l}$ group. However, there were no significant differences in genotype frequency distributions of the MTHFR C677T, $\beta-F g-148 T / C$ and ApoE ع2-4 polymorphisms for the parameters of FBG, TC, TG and LDL-C (Table I).

Table SIII indicates the association between the BMI, ACE I/D, $\beta-F g-455 A / G$ and PAI-1 4G/5G gene polymorphisms. The frequency of the ACE genotype DD in obese $\left(\mathrm{BMI} \geq 28.00 \mathrm{~kg} / \mathrm{m}^{2}\right)$ and overweight $(28.00>\mathrm{BMI}$ $\geq 24.00 \mathrm{~kg} / \mathrm{m}^{2}$ ) subjects was higher than that in normal subjects $\left(24.00>\mathrm{BMI} \geq 18.5 \mathrm{~kg} / \mathrm{m}^{2}\right)$. As presented in Table SIV, the $\mathrm{D}$ allele of the ACE gene was associated with a high BMI.
Furthermore, a significant association between $\beta$-Fg-455 gene polymorphisms and the BMI was observed (Table SIII). The relationship between the PAI-1 gene and the BMI is presented in Table SIII. The frequency of the AA genotype of the $\beta-F g-455$ gene in obese subjects was $\sim 8 \%$ higher than that in normal subjects, while that in overweight subjects was $\sim 6 \%$ higher $(\mathrm{P}<0.05)$. Furthermore, the frequency of the PAI-1 5G5G genotype in obese and overweight subjects was significantly higher than that in normal subjects $(\mathrm{P}<0.05)$. However, there was no significant difference in the MTHFR C677T, $\beta$-Fg-148T/C and ApoE ع2-4 genotypes between groups of high/low HDL-C, ALT and AST (Table SIII).

Predictive value of clinical laboratory parameters for IS. As presented in Table III, high levels of FBG, TG and LDL-C were risk factors for IS. The results suggested that the risk of IS increased by 6.47-, 4.64- and 7.62-fold along with each 1-mmol/1 increment of FBG, TG and LDL-C, respectively. Age and sex were included for adjusting in model 2 and these 
Table III. Prediction of ischemic stroke by laboratory parameters.

\begin{tabular}{|c|c|c|c|c|c|c|c|c|}
\hline \multirow[b]{3}{*}{ Factor } & \multicolumn{4}{|c|}{ Model 1} & \multicolumn{4}{|c|}{ Model 2} \\
\hline & \multirow[b]{2}{*}{ OR } & \multicolumn{2}{|c|}{$95 \% \mathrm{CI}$} & \multirow[b]{2}{*}{ P-value } & \multirow[b]{2}{*}{ OR } & \multicolumn{2}{|c|}{$95 \% \mathrm{CI}$} & \multirow[b]{2}{*}{ P-value } \\
\hline & & Lower & Upper & & & Lower & Upper & \\
\hline $\mathrm{FBG}(\mathrm{mmol} / \mathrm{l})$ & 6.47 & 3.95 & 10.61 & $<0.001$ & 5.38 & 3.25 & 8.91 & $<0.001$ \\
\hline $\mathrm{TC}(\mathrm{mmol} / \mathrm{l})$ & 0.34 & 0.10 & 1.13 & 0.077 & 0.44 & 0.15 & 1.28 & 0.130 \\
\hline $\mathrm{TG}(\mathrm{mmol} / \mathrm{l})$ & 4.64 & 2.09 & 10.32 & $<0.001$ & 5.41 & 2.28 & 12.81 & $<0.001$ \\
\hline LDL-C (mmol/l) & 7.62 & 1.60 & 36.40 & 0.011 & 6.21 & 1.59 & 24.16 & 0.008 \\
\hline
\end{tabular}

Model 1 is unadjusted and model 2 is adjusted for age and sex. OR, odds ratio; FBG, fasting blood glucose; TC, total cholesterol; TG, triglyceride; LDL-C, low-density lipoprotein cholesterol.

Table IV. ROC curve analysis of laboratory parameters for ischemic stroke.

\begin{tabular}{lcccccr}
\hline & & & & & \multicolumn{2}{c}{$95 \% \mathrm{CI}$} \\
\cline { 5 - 7 } Parameter & Cut-off point & Specificity & Sensitivity & AUC & Lower & Upper \\
\hline FBG $(\mathrm{mmol} / \mathrm{l})$ & 5.27 & 0.833 & 0.694 & 0.828 & 0.784 & 0.867 \\
TC $(\mathrm{mmol} / \mathrm{l})$ & 5.12 & 0.994 & 0.265 & 0.595 & 0.541 & 0.648 \\
TG $(\mathrm{mmol} / \mathrm{l})$ & 1.32 & 0.833 & 0.471 & 0.702 & 0.650 & 0.751 \\
LDL-C (mmol/l) & 3.36 & 0.999 & 0.284 & 0.638 & 0.584 & 0.689 \\
\hline
\end{tabular}

ROC, receiver operating characteristic; AUC, area under the ROC curve; FBG, fasting blood glucose; TC, total cholesterol; TG, triglyceride; LDL-C, low-density lipoprotein cholesterol.

risk values increased to 5.38-, 5.41- and 6.21-fold for FGB, TG and LDL, respectively. The results in Table SV suggested that a high BMI is a risk factor for IS. It was indicated that with the increase of the BMI by $1 \mathrm{~kg} / \mathrm{m}^{2}$, the risk increased by 2.26-fold. When age and sex were included for adjusting in model 2 , the risk increased by 2.35 -fold. HDL-C was indicated to be a protective factor against IS. With the increase of HDL-C by $1 \mathrm{mmol} / 1$, the risk of disease was reduced to $27 \%$ and after adjustment for age and sex, it was $32 \%$.

ROC curve analysis of laboratory parameters for IS. Area under the curve values at the $95 \%$ confidence interval (95\% CI) for IS predicted by laboratory parameters were as follows: FBG, 0.828 (0.784-0.867); TC, 0.595 (0.541-0.648); TG, 0.702 (0.650-0.751); LDL-C, 0.638 (0.584-0.689); and BMI, 0.735 (0.685-0.786) (Tables IV, SVI and Fig. S1). It was observed that FBG had better specificity (0.833) and sensitivity (0.694) for predicting IS compared to the other parameters. The optimal cut-off point of FGB for predicting IS was $5.27 \mathrm{mmol} / \mathrm{l}$. Among the five parameters, LDL-C had the highest specificity (0.999) with an optimal cut-off point for predicting IS of $3.36 \mathrm{mmol} / 1$. The sensitivity values of TC, TG, LDL-C and BMI for predicting IS were poor $(0.265,0.471,0.284$ and 0.591 , respectively), although their specificity values were better.

The relationships between IS and allele frequencies of ACE I/D, MTHFR C677T, $\beta$-Fg-455A/G, $\beta$-Fg-148T/C, PAI-1
4G/5G and ApoE ع2-4 genes are presented in Table V and Fig. 2. Significant differences in the genotype frequencies of ACE I/D, $\beta$-Fg-455 A/G and $\beta$-Fg-148 T/C genes between patients with IS and the control group were present (Fig. 2). However, only the allele frequencies of ACE I/D and $\beta-F g-148$ $\mathrm{T} / \mathrm{C}$ were significantly different between the two groups (Table V). More specifically, the frequencies of the D allele of $\mathrm{ACE} \mathrm{I} / \mathrm{D}$ and the $\mathrm{C}$ allele of $\beta$-Fg-148 T/C were higher in the IS group, whereas the frequencies of the I allele of ACE I/D and the $\mathrm{T}$ allele of $\beta-\mathrm{Fg}-148 \mathrm{~T} / \mathrm{C}$ in the IS group were lower compared with those in the control group.

\section{Discussion}

Strokes are the second leading cause of death and the leading cause of permanent disability in adults worldwide (25), with IS accounting for $85 \%$ of the total number of strokes (26). IS is caused by the occlusion of major arteries or branches of the brain, which leads to vascular occlusion and deprivation of oxygen and energy. This is followed by the formation of reactive oxygen species, then the release of glutamate, the accumulation of intracellular calcium and the induction of inflammatory processes (27). Previous studies have reported that IS is closely related to certain genes, as well as blood glucose and blood lipid levels (28-31). However, it is currently not possible to control or treat stroke at the genetic level. To explore this possibility, the relationships between IS and 

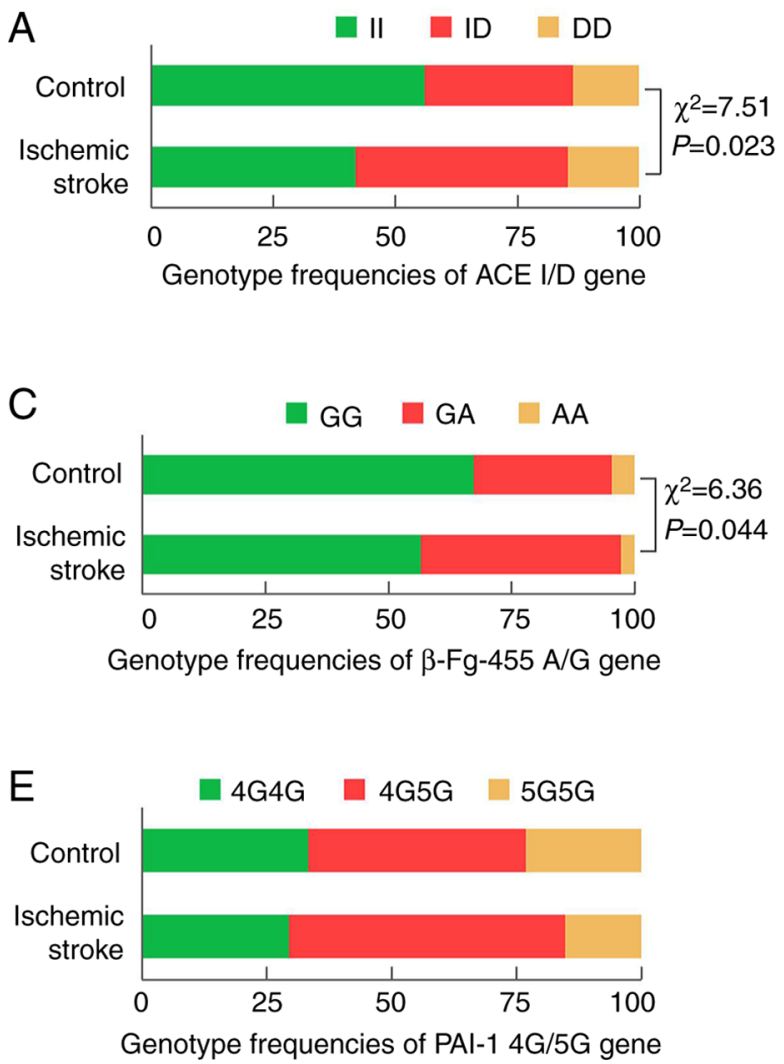

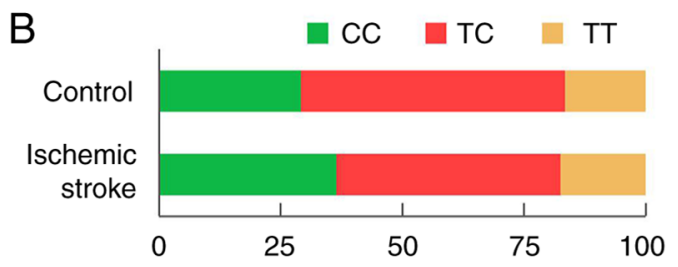

Genotype frequencies of MTHFR C677T gene

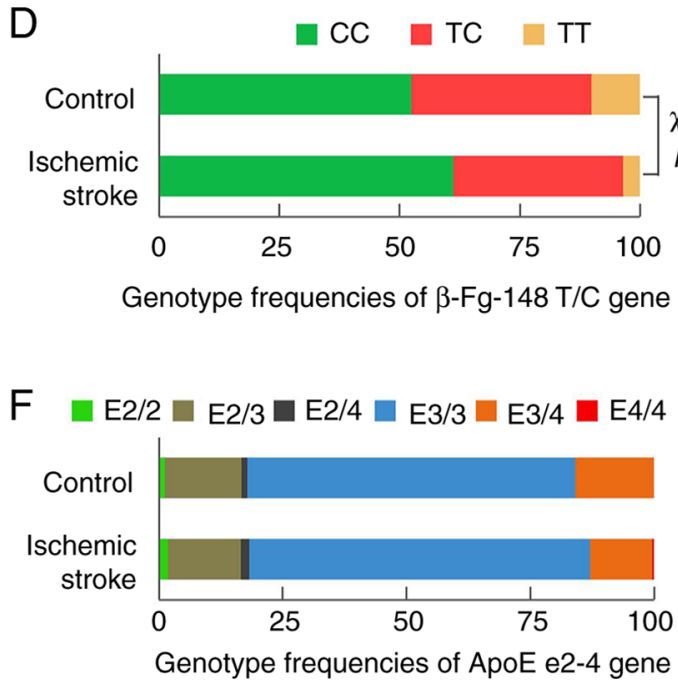

Figure 2. Association of ischemic stroke with genotype frequencies of (A) ACE I/D, (B) MTHFR C677T, (C) $\beta$-Fg-455 A/G, (D) $\beta$-Fg-148 T/C, (E) PAI-1 4G/5G and (F) ApoE ع2-4. ACE, angiotensin-converting enzyme; MTHFR, methylene tetrahydrofolate reductase; $\beta$-Fg, $\beta$-fibrinogen; PAI, plasminogen activator inhibitor; ApoE, apolipoprotein E.

genetic and laboratory parameters (FBG, TC, TG, LDL-C, HDL-C, ALT, AST and BMI) were examined in the present study.

The results of the present study revealed correlations between IS and the ACE I/D, $\beta-F g-455 \mathrm{~A} / \mathrm{G}$ and $\beta-\mathrm{Fg}-148 \mathrm{~T} / \mathrm{C}$ polymorphisms. Frequencies of both the D allele of ACE $\mathrm{I} / \mathrm{D}$ and the $\mathrm{C}$ allele of $\beta-\mathrm{Fg}-148 \mathrm{~T} / \mathrm{C}$ in the IS group were higher than those in the control group, suggesting that IS is closely related to the D allele of those two alleles, which is consistent with the studies performed by Zhao et al (32) and Wu et al (33).

In accordance with the results of a study by Lin et al (30), the present results indicated that FBG was an effective parameter for predicting IS, suggesting that routine monitoring for FBG may effectively control and prevent the progression of IS. In a study performed by Anderson et al (34), hyperglycemia was indicated to affect mitochondrial function in the ischemic penumbra, resulting in cortical acidosis and cell death. Hyperglycemia also impaired cerebrovascular reactivity in the microvasculature, which may disturb reperfusion after recanalization (35). Diabetes or hyperglycemia may alter blood-brain barrier permeability and induce disruption of the blood-brain barrier, which may aggravate the formation of brain edema and lead to hemorrhagic transformation (36). In addition, the results of the present study suggested that hyperlipidemia is a risk factor for IS. Lee et al (31) pointed out that a high TG level is a risk factor for IS and that the risk is 1.28-fold higher than that of individuals with normal TG levels. Lee et al (31) also noted that the presence of LDL-C $\geq 130 \mathrm{mg} / \mathrm{dl}$ may increase the risk of IS. Furthermore, Pawelczyk et al (37) reported a significant increase in the plasma concentration of soluble P-selectin (sP-selectin) in patients with stroke and hyperlipidemia and hyperglycemia compared with normolipidemic/normoglycemic patients with stroke. On the one hand, a strong positive correlation was observed between hyperglycemia and sP-selectin levels, which emphasizes the leading role of hyperglycemia in atherothrombosis progression. On the other hand, hyperlipidemia was also associated with an increase in the plasma sP-selectin level (37). This glycoprotein has a role in stimulating the release of procoagulant microparticles, which induces a procoagulant state (38).

Methods to treat IS mainly comprise initial treatment with intra-arterial thrombolysis, endovascular mechanical thrombectomy and antiplatelet treatment (39). However, such treatments rarely negate the possibility of recurrence of IS. Studying associations of stroke-related genes with blood glucose and blood lipids may offer alternative approaches. The present results suggested that LDL-C and TG were closely related to the ACE I/D, $\beta-\mathrm{Fg}-455 \mathrm{~A} / \mathrm{G}$ and PAI-1 4G/5G polymorphisms, consistent with the results of $\mathrm{Li}$ (40) and Guney et al (41). The results of the present study also indicated that hyperlipidemia was correlated with the D allele of ACE I/D, which confirmed the results of Suzuki et al (42) and Lee and Tsai (43), who demonstrated positive associations of hyperlipidemia with the DD genotype and D allele frequency of ACE I/D.

There are certain limitations to the present study. First, the study enrolled patients with IS at a hospital rather than patients 
from a community-based general population. Furthermore, the study comprised a single population with limited sample size; thus, the results require to be confirmed in multiple centers using larger sample sizes and in different ethnic populations. In addition, the study did not collect data on several other major risk parameters of IS (such as homocysteine, fibrinogen or prothrombin), which should also be examined in future research. Finally, dietary habits exhibited a marked variation among the participants making it is difficult to assess the impact of dietary habits on IS in the present study.

In summary, the present study indicated that the $\mathrm{D}$ allele of ACE I/D and the C allele of $\beta-\mathrm{Fg}-148 \mathrm{~T} / \mathrm{C}$ were significantly associated with IS and that the frequency of the $D$ allele of ACE I/D was significantly higher in individuals with hyperlipidemia. High levels of FGB, TG, LDL-C and BMI were risk factors for IS, with optimal predictive cut-off points of $5.27,1.32$ and $3.36 \mathrm{mmol} / 1$ and $23.12 \mathrm{~kg} / \mathrm{m}^{2}$, respectively. The present results suggested that individuals with hyperlipidemia or a high frequency of the D allele of ACE I/D may be at risk of IS. By contrast, there were no significant differences in TC levels and the MTHFR C677T, PAI-1 4G/5G and ApoE ع2-4 gene polymorphisms between patients with IS and controls. Identifying the relationships among IS, stroke-related genes and blood lipid and blood glucose levels may lead to a better understanding of the pathophysiology of IS in the Chinese Han population and may provide a reasonable control range of laboratory parameters for the prevention of IS in patients with diabetes and hyperlipidemia as early as possible.

\section{Acknowledgements}

The authors thank Dr Michelle Kahmeyer-Gabbe for editing the English text of a draft of this manuscript.

\section{Funding}

This work was supported by the National Natural Science Foundation of China (grant nos. 81974314, 81873975, 81802084 and 81902984), the Excellent Academic Leader Training Program of Shanghai Health System (grant no.2018BR31), the Medical Guidance Science and Technology Support Project of Shanghai (grant no. 19411964800) and the Clinical Research and Cultivation Project of Shanghai Tongji Hospital [grant nos. ITJ(ZD)1803, ITJ(ZD)1905 and $\operatorname{ITJ}(\mathrm{QN}) 1905]$.

\section{Availability of data and material}

The datasets used and/or analyzed during the current study are available from the corresponding author on reasonable request.

\section{Authors' contributions}

JW and XC collected the data and performed the statistical analysis and interpretation of the result. ZS analyzed the patient data, wrote the manuscript and approved the final version. YY, JW and WQ acquired, analyzed, and interpreted the data for the work. PN and DL designed the overall study 
and revised the manuscript, and also checked and approved the authenticity of the raw date. All authors read and approved the manuscript.

\section{Ethics approval and consent to participate}

This study was approved by the ethics committee of Shanghai Tongji Hospital (Shanghai, China) and was performed according to the Declaration of Helsinki. All participants provided written informed consent. If the subjects were unable to communicate, written informed consent was obtained from their legal relatives.

\section{Patient consent for publication}

Not applicable.

\section{Competing interests}

The authors declare that they have no competing interests.

\section{References}

1. Feigin VL, Lawes CM, Bennett DA, Barker-Collo SL and Parag V: Worldwide stroke incidence and early case fatality reported in 56 population-based studies: A systematic review. Lancet Neurol 8: 355-369, 2009.

2. Sacco RL, Kasner SE, Broderik JP, Caplan LR, Connors JJ, Culebras A, Elkind MS, George MG, Hamdan AD, Higashida RT, et al: An updated definition of stroke for the 21st century: A statement for healthcare professionals from the American heart association/American stroke association. Stroke 44: 2064-2089, 2013.

3. Liu L, Wang D, Wong KS and Wang Y: Stroke and stroke care in China: Huge burden, significant workload, and a national priority. Stroke 42: 3651-3654, 2011.

4. Feigin VL, Roth GA, Naghavi M, Parmar P, Krishnamurthi R, Chugh S, Mensah GA, Norrving B, Shiue I, Ng M, et al: Global burden of stroke and risk factors in 188 countries, during 1990-2013: A systematic analysis for the global burden of disease study 2013. Lancet Neurol 15: 913-924, 2016.

5. Liang C, Ni G, Ma J, Liu H, Mao Z, Sun H and Zhang X: Impact of tag single nucleotide polymorphisms (SNPs) in CCL11 gene on risk of subtypes of ischemic stroke in Xinjiang Han populations. Med Sci Monit 23: 4291-4298, 2017.

6. Bersano A, Ballabio E, Bresolin N and Candelise L: Genetic polymorphisms for the study of multifactorial stroke. Hum Mutat 29: 776-795, 2008.

7. Huen K, Yousefi P, Street K, Eskenazi B and Holland N: PON1 as a model for integration of genetic, epigenetic, and expression data on candidate susceptibility genes. Environ Epigenet 1: dvv003, 2015.

8. Zhang Z, Xu G, Liu D, Fan X, Zhu W and Liu X: Angiotensin-converting enzyme insertion/deletion polymorphism contributes to ischemic stroke risk: A meta-analysis of 50 case-control studies. PLoS One 7: e46495, 2012.

9. Tuncer N, Tuglular S, Kılıç G, Sazci A, Us O and Kara I: Evaluation of the angiotensin-converting enzyme insertion/ deletion polymorphism and the risk of ischaemic stroke. J Cli Neurosci 13: 224-227, 2006.

10. Pera J, Slowik A, Dziedzic T, Wloch D and Szczudlik A: ACE I/D polymorphism in different etiologies of ischemic stroke. Acta Neurol Scand 114: 320-322, 2006.

11. Liu J, Sun K, Bai Y, Zhang W, Wang X, Wang Y, Wang H, Chen J, Song X, Xin Y, et al: Association of three-gene interaction among MTHFR, ALOX5AP and NOTCH3 with thrombotic stroke: A multicenter case-control study. Hum Genet 125: 649-656, 2009.

12. Arina CA, Amir D, Siregar Y and Sembiring RJ: The Role of polymorphism gen methylene tetra hydrofolate reductase (MTHFR) C677T in ischaemic stroke patients with and without hypertension. Open Access Maced J Med Sci 7: 29-32, 2019.
13. Coen Herak D, Lenicek Krleza J, Radic Antolic M, Horvat I, Djuranovic V, Zrinski Topic R and Zadro R: Association of polymorphisms in coagulation factor genes and enzymes of homocysteine metabolism with arterial ischemic stroke in children. Clin Appl Thromb Hemost 23: 1042-1051, 2017.

14. Kopyta I, Niemiec P, Balcerzyk A, Emich-Widera E, Pilarska E, Pienczk-Ręcławowicz K, Kaciński M, Wendorff J, Nowak T, Iwanicki T, et al: Fibrinogen alpha and beta gene polymorphisms in pediatric stroke-case-control and family based study. Eur J Paediatr Neurol 19: 176-180, 2015.

15. Kumar A, Misra S, Kumar P, Sagar R and Prasad K: Association between beta-fibrinogen C148T gene polymorphism and risk of ischemic stroke in a north Indian population: A case-control study. Pulse (Basel) 4: 165-171, 2017.

16. Hu X, Zan X, Xie Z, Li Y, Lin S, Li H and You C: Association between plasminogen activator inhibitor-1 genetic polymorphisms and stroke susceptibility. Mol Neurobiol 54: 328-341, 2017.

17. Eriksson P, Kallin B, Van't Hooft FM, Båvenholm P and Hamsten A: Allele-specific increase in basal transcription of the plasminogen-activator inhibitor 1 gene is associated with myocardial infarction. Proc Natl Acad Sci USA 92: 1851-1855, 1995.

18. Iacoviello L, Burzotta F, Di Castelnuovo A, Zito F, Marchioli R and Donati MB: The $4 \mathrm{G} / 5 \mathrm{G}$ polymorphism of PAI-1 promoter gene and the risk of myocardial infarction: A meta-analysis. Thromb Haemost 80: 1029-1030, 1998.

19. Jood K, Ladenvall P, Tjärnlund-Wolf A, Ladenvall C, Andersson M, Nilsson S, Blomstrand C and Jern C: Fibrinolytic gene polymorphism and ischemic stroke. Stroke 36: 2077-2081, 2005.

20. Wiklund PG, Nilsson L, Ardnor SN, Eriksson P, Johansson L, Stegmayr B, Hamsten A, Holmberg D and Asplund K: Plasminogen activator inhibitor-1 4G/5G polymorphism and risk of stroke: Replicated findings in two nested case-control studies based on independent cohorts. Stroke 36: 1661-1665, 2005.

21. Mahley RW and Rall SC Jr: Apolipoprotein E: Far more than a lipid transport protein. Annu Rev Genomics Hum Genet 1: 507-537, 2000

22. Pezzini A, Grassi M, Del Zotto E, Bazzoli E, Archetti S, Assanelli D, Akkawi NM, Albertini A and Padovani A: Synergistic effect of apolipoprotein E polymorphisms and cigarette smoking on risk of ischemic stroke in young adults. Stroke 35: 438-442, 2004.

23. Sturgeon JD, Folsom AR, Bray MS, Boerwinkle E and Ballantyne CM; Atherosclerosis Risk in Communities Study Investigators: Apolipoprotein E genotype and incident ischemic stroke: The aherosclerosis rsk in cmmunities sudy. Stroke 36: 2484-2486, 2005.

24. Chinese Neurology Association: Chinese guidelines for the diagnosis and treatment of acute ischemic stroke in 2014. Chin J Neurol 48: 246-257, 2015.

25. Murray CJ and Lopez AD: Measuring the global burden of disease. N Engl J Med 369: 448-457, 2013.

26. Beal CC: Gender and stroke symptoms: A review of the current literature. J Neurosci Nurs 42: 80-87, 2010.

27. Fluri F, Schuhmann MK and Kleinschnitz C: Animal models of ischemic stroke and their application in clinical research. Drug Des Devel Ther 9: 3445-3454, 2015.

28. Li G, Liu Y, Li X, Ning Z, Sun Z, Zhang M, Lu Y, Wu L and Wang L: Association of PAI-1 4G/5G polymorphism with ischemic stroke in Cinese patients with type 2 diabetes mellitus. Genet Test Mol Biomarkers 22: 554-560, 2018.

29. Zhao LL, Su G, Chen LX, Yan Q, Wang XP, Yuan W, Wang L and Zhang ZC: Apolipoprotein E polymorphisms are associated with ischemic stroke susceptibility in a Northwest China Han population. Biosci Rep 37: BSR20171088, 2017.

30. Lin CC, Yang CP, Li CI, Liu CS, Chen CC, Lin WY, Hwang KL, Yang SY and Li TC: Visit-to-visit variability of fasting plasma glucose as predictor of ischemic stroke: Competing risk analysis in a national cohort of Taiwan diabetes study. BMC Med 12: 165, 2014.

31. Lee JS, Chang PY, Zhang Y, Kizer JR, Best LG and Howard BV: Triglyceride and HDL-C dyslipidemia and risks of coronary heart disease and ischemic stroke by glycemic dysregulation status: The strong heart study. Diabetes Care 40: 529-537, 2017.

32. Zhao J, Qin X, Li S and Zeng Z: Association between the ACE I/D polymorphism and risk of ischemic stroke: An updated meta-analysis of 47,026 subjects from 105 case-control studies. J Neuro Sci 345: 37-47, 2014. 
33. Wu G, Cai H, Cai H, Chen Z, Tan L, Qi H and Cai Y: Effect of the-148C/T, 448G/A, and -854G/A polymorphisms of the $\beta$-fibrinogen gene on the risk of ischemic stroke in Chinese population. J Stroke Cerebrovasc Dis 24: 1577-1590, 2015.

34. Anderson RE, Tan WK, Martin HS and Meyer FB: Effects of glucose and $\mathrm{PaO} 2$ modulation on cortical intracellular acidosis, NADH redox state, and infarction in the ischemic penumbra. Stroke 30: 160-170, 1999.

35. Kawai N, Keep RF and Betz AL: Hyperglycemia and the vascular effects of cerebral ischemia. Stroke 28: 149-154, 1997.

36. Dietrich WD, Alonso O and Busto R: Moderate hyperglycemia worsens acute blood-brain barrier injury after forebrain ischemia in rats. Stroke 24: 111-116, 1993.

37. Pawelczyk M, Kaczorowska B and Baj Z: The impact of hyperglycemia and hyperlipidemia on plasma P-selectin and platelet markers after ischemic stroke. Arch Med Sci 13: 1049-1056, 2017.

38. Nomura S, Inami N, Iwasaka T and Liu Y: Platelet activation markers, microparticles and soluble adhesion molecules are elevated in patients with arteriosclerosis obliterans: Therapeutic effects by cilostazol and potentiation by dipyridamole. Platelets 15: 167-172, 2004.

39. Powers WJ, Rabinstein AA, Ackerson T, Adeoye OM, Bambakidis NC, Becker K, Biller J, Brown M, Demaerschalk BM, Hoh B, et al: 2018 Guidelines for the early management of patients with acute ischemic stroke: A guideline for healthcare professionals from the American heart association/American stroke association. Stroke 49: e46-e110, 2018.
40. Li YY: Plasminogen activator inhibitor-1 4G/5G gene polymorphism and coronary artery disease in the Chinese Han population: A meta-analysis. PLoS One 7: e33511, 2012.

41. Guney AI, Ergec D, Kirac D, Ozturhan H, Caner M, Koc G, Kaspar C, Ulucan K and Agirbasli M: Effects of ACE polymorphisms and other risk factors on the severity of coronary artery disease. Genet Mol Res 12: 6895-6906, 2013.

42. Suzuki T, Yokota H, Yamazaki T, Kitamura K, Yamaoki K, Nagai R and Yazaki Y: Angiotensin converting enzyme polymorphism is associated with severity of coronary heart disease and serum lipids (total cholesterol and triglycerides levels) in Japanese patients. Coron Artery Dis 7: 371-375, 1996.

43. Lee YJ and Tsai JC: ACE gene insertion/deletion polymorphism associated with 1998 world health organization definition of metabolic syndrome in Chinese type 2 diabetic patients. Diabetes Care 25: 1002-1008, 2002.

This work is licensed under a Creative Commons Attribution-NonCommercial-NoDerivatives 4.0 International (CC BY-NC-ND 4.0) License. 